\title{
Effect of Hemsball Shooting on Fine Motor Proficiency in Hearing Impaired Children
}

\author{
Meltem Işık \& İbrahim Kılıç ${ }^{2}$ \\ ${ }^{1}$ School of Physical Education and Sport, Afyon Kocatepe University, Afyonkarahisar, Turkey \\ ${ }^{2}$ Biostatistics, Afyon Kocatepe University, Afyonkarahisar, Turkey \\ Correspondence Meltem Işık, Faculty of Sport Science, Aydın Adnan Menderes University, Aydin, 09010, Turkey. \\ E-mail: isik.meltem@adu.edu.tr
}

Received: September 14, 2020

Accepted: December 21, 2020

Online Published: March 10, 2021

doi:10.5539/ies.v14n4p11

URL: https://doi.org/10.5539/ies.v14n4p11

\begin{abstract}
In this study, which was designed in pre-test - post-test and experimental-control model, it was aimed to determine the effect of hemsball shooting techniques on fine motor proficiency and manual dexterity in hearing-impaired children between the age range of 7-11. The study group was composed of 26 children (13 for the experimental group +13 for the control group) aged between 7-11 years old with hearing loss above $56 \mathrm{~dB}$ and having no second impairment and sports background. The children in the experimental group were subjected to a training program to improve their fine motor skills and manual dexterity for three days a week, one hour each day throughout 10 weeks, which involved hemsball shooting techniques. Fine motor proficiency and manual dexterity of hearing-impaired children were measured by the three sub-tests (fine motor precision, fine motor integration, manual dexterity) of Bruiniks-Oseretsky Test of Motor Proficiency (BOT-2). In the research, the group experiment-control and measurements (pre-test - post-test) were compared with independent samples t-test and paired samples t-test. As a result of the study, it was revealed that hemsball shooting techniques had a significant effect on the fine motor proficiency levels of hearing-impaired children, including fine motor precision, fine motor integration, and manual dexterity. Furthermore, it was determined that the effect of hemsball shooting techniques on motor proficiency did not differ significantly according to gender and that the application performed had positive effects on both girls and boys.
\end{abstract}

Keywords: hearing impaired, hemsball, fine motor proficiency, manual dexterity, Bot-2, special education

\section{Introduction}

Adequate motor skill development has important in the development of children in terms of lifelong maintenance of physical activity and sports participation in children as well as language, speech, cognitive, social, and academic development (Krombholz, 2006). Therefore, physical activity and individual movement experiences are important in the progression from the period of basic movements to the period of sports-related movements (Gallahue \& Ozmun, 1995). Because physical activity offers children the opportunity to develop adequate motor skills (Fisher et al., 2005; Wrotniak, Epstein, Dorn, Jones, \& Kondilis, 2006). The vestibular system that affects motor skill development is important in postural mechanism and muscle control. The problems that may occur in the muscle control and balance due to the impress on the vestibular system in hearing-impaired individuals negatively affect the muscle strength and motor functions (Rapin, 1974; Wiegersma \& Velde, 1983; Horvat, 1990; Rine et al., 2000; Gheysen, Loots, \& Waelvelde, 2008; Rajendran \& Roy, 2011; Melo, Lemos, Macky, Raposo, \& Ferraz, 2015). Concomitant processes such as auditory deprivation and vestibular deficiency may interfere with the sensorimotor function which leads to the special development of psychomotor skills. The researches revealed that hearing-impaired children have deficiencies and delays in psychomotor development and manual dexterity (such as buttoning up, writing, painting, drawing, holding a racket, playing an instrument, and sewing) (Wiegersma \& Velde, 1983; Winnick, 2005; Payne, 2008; Gheysen et al., 2008; Rajendran \& Roy, 2011; Melo et al., 2015). It is well known that providing early diagnosis, early treatment, and early education opportunities for advanced hearing impaired children can improve their fine motor development (Häger \& Rösblad, 2002). Most of the activities in daily life require adequate use of fine motor skills (Wrotniak et al., 2006; Smith \& Brien, 2013).

Bruininks and Bruininks (2005) considered fine motor skills as "the control and coordination of distal muscles 
by the hands and fingers". This definition is divided into two different components: Fine motor integration was conceptualized as a manual ability that requires the processing of a visual stimulus to produce synchronized hand movements and adequate motor output, and fine motor precision was conceptualized as a fine manual dexterity based on a minimum visual-perceptual component. On the other hand, manual dexterity was defined as the individual's ability to manipulate the objects with his/her hands (Houwen, Visscher, Lemmink, \& Hartman, 2009). Fine motor skills are an indispensable part of motor skills (Smith, 2000) and an important tool in interacting with the environment (Smith \& Brien, 2013). The researchers emphasized that the activities for fine motor development in hearing-impaired children may be associated with beginning to take self-care responsibilities at an early age and that skill development can be facilitated through active experiences (Yaman \& Erturan, 1999). The purpose of the skills with small muscle groups is to ensure that the movement is performed clearly and accurately with details rather than generating force. The human hand is important in practicing the sensitive and fine movements necessary for performing daily life activities and playing games (Moreira, Magalhães, \& Alves, 2014).

Hemsball, which enables the effective use of hand and fingers to apply shooting techniques during the game, has an important effect on individuals' fine motor skill development. Hemsball, which is a new type of sport that can be played by everyone, requires manual dexterity and fine motor proficiency while applying the shooting techniques as well as focusing on the moves, hand-eye-foot coordination, and the ability to balance due to the constant change of positioning during the game (Hemsball, 2011; Gönülateş, 2017; Işık \& Zorba, 2018).

Hemsball was revealed as an idea by Altınay in 2011 and appeared as a game as a result of Research and Development studies. It was approved by the Turkish Ministry of Youth and Sports in 2013 as a sport branch. In hemsball, the goal is to send the hemsball into the hemsball circle on the hemsball target board on the floor, without touching the hoop so that it falls into the field of the opponent. There are thirty shooting techniques developed to achieve this goal (Hemsball, 2011). In the training program, there were various shooting techniques such as alçacık, bilye, çatal, firıldak, firtına, tırnak, hortum and teke, which required the use of fingers more actively.

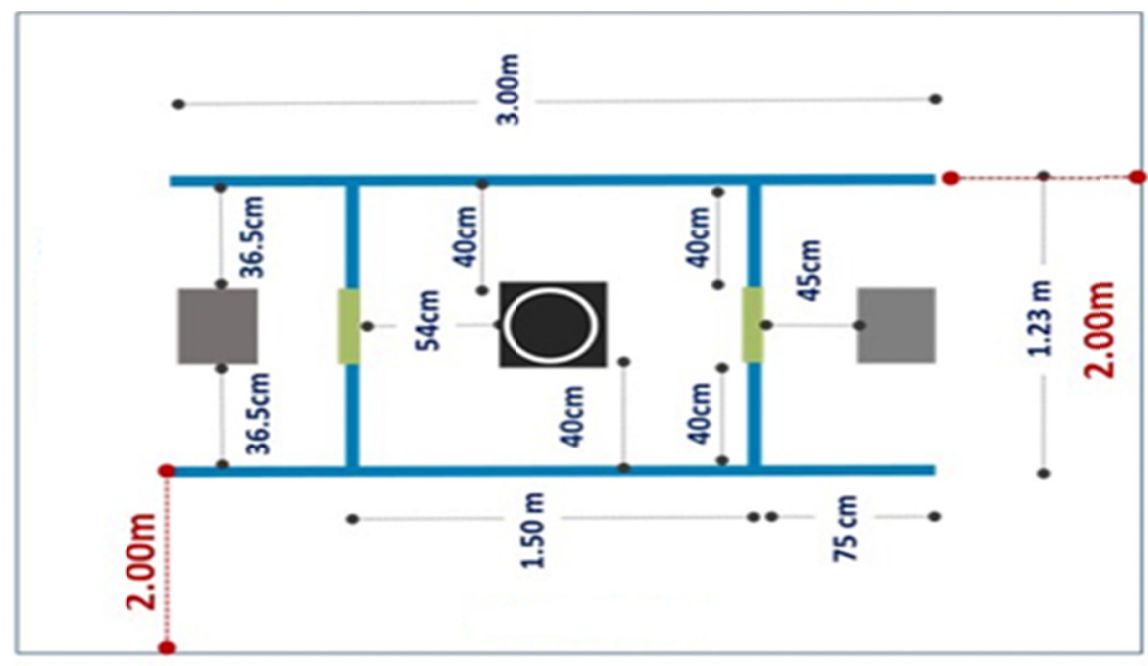

Figure 1. International hemsball juniors pitch

The fact that hemsball is a new sports branch, that this sport can be easily played in any setting, that the number of studies on hemsball (Todorova et al., 2014; Tuğlu, 2016; Işık, 2016; Sever et al., 2016) and researches on the sensitive movements of hearing-impaired children are extremely limited, and that no scientific studies are investigating the effect of hemsball on fine motor proficiency and manual dexterity of hearing-impaired children manifests the importance of this study. For this study, the study hypothesized that hemsball shooting techniques had a significant and positive effect on the fine motor proficiency of hearing-impaired children.

In this regard, the purpose of the study was to determine the effect of hemsball shooting techniques on fine motor proficiency and manual dexterity in hearing-impaired children between the age range of 7-11. 


\section{Method}

The population of this study, which was conducted in pre-test - post-test and experimental-control model, was composed of the children between the age range of 7-11 who were studying in the school for hearing impaired children, who had a hearing loss over $56 \mathrm{~dB}$, with no second impairment and sports background. The data group of the study was composed of hearing-impaired children studying in the schools for hearing impaired children available in Afyonkarahisar and Kütahya provinces in Turkey. The experimental group was composed of 13 children studying in the school for hearing impaired children in Afyonkarahisar province and the control group was composed of 13 children studying in the school for hearing impaired children in Kütahya province, which was a total of 26 hearing-impaired children. Informing the experimental and control groups; the homogeneity of such factors as having no second impairment and sports background, hearing loss level, age, and gender were taken into consideration. Of the children aged between 7 and $11,46.2 \%(n=12)$ were girls and $53.8 \%(n=14)$ were boys. The children in the experimental group were subjected to a training program to improve their fine motor skills and manual dexterity for three days a week, one hour each day throughout 10 weeks, which involved hemsball shooting techniques.

\subsection{Hemsball Training Program}

The first coaching courses for Hemsball were initiated by the Turkish Sport for All Federation in 2014 and the coaching courses have been held since then. In the coaching training and development seminars held, Altınay and his team introduced the rules and shooting techniques of the game (Hemsball, 2011). Besides, the work "Hemsball Sport for All Ages", which included the rules, shooting techniques, and exercises of the game, was published in 2017 (Gönülateş, 2017). This study, which included the 30 shooting techniques of the hemsball branch, also involved the techniques of "alçacık, bilye, çatal, firıldak, firtına, tırnak, hortum, teke" in which fingers and wrists were used more actively. Images of these shooting techniques are presented below. 


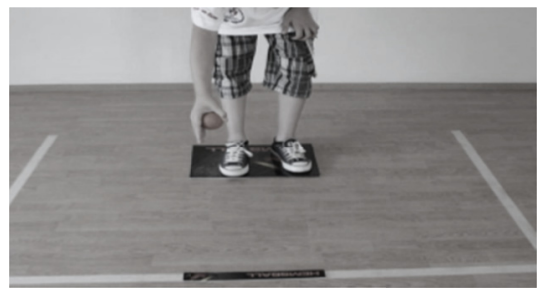

Alçacık: The hand holding the ball in the palm-up position is brought to the knee level in front of the body. The ball is thrown from the pinkie finger while the wrist is circling from inside out.

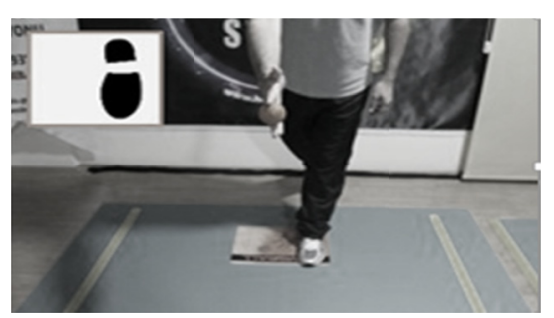

Çatal: The ball is clinched between the forefinger and the middle finger. During shooting, the arm held in front of the body is bent from the elbow and the ball is released from the fingers while the arm is moved forward.

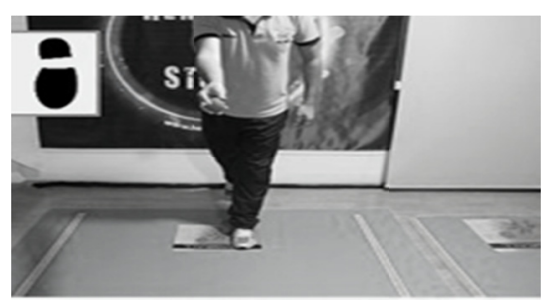

Furtına: The ball is grasped by the first knuckles of all the fingers and the ballpoints the cross line. During shooting, the elbow is bent, the ball is retracted to the chest, the dominant hand holding the ball is rotated outside and the ball is thrown strongly.
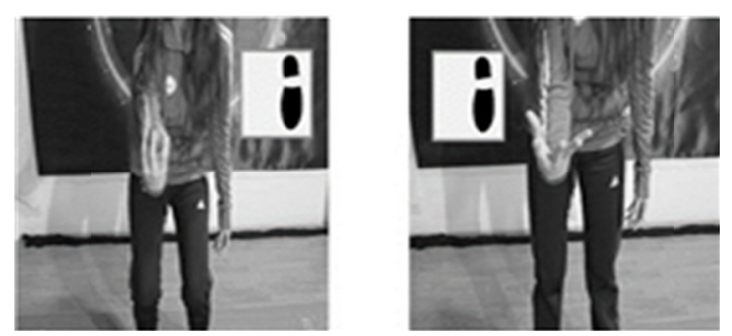

Hortum: The ball, which is held with the first knuckles of all the fingers, is thrown towards the target by moving the wrist from inside out and opening the fingers.

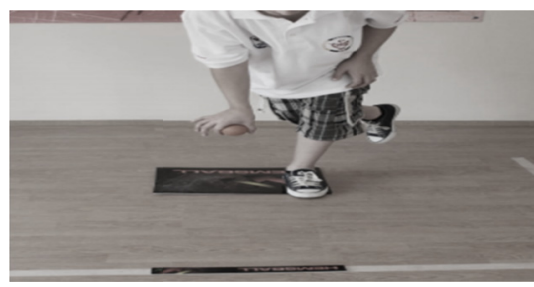

Bilye: The hand holding the ball between the thumb and forefinger is pulled backward and the ball is thrown by releasing the fingers forward.

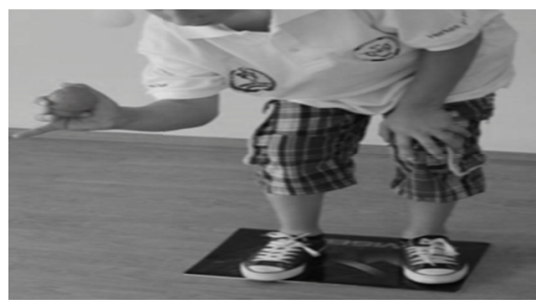

Firldak: The ball is grasped with the thumb, forefinger, and middle finger. Before shooting, the thumb, forefinger, and middle finger are rotated clockwise and the ball is thrown by rotating it counterclockwise during shooting.

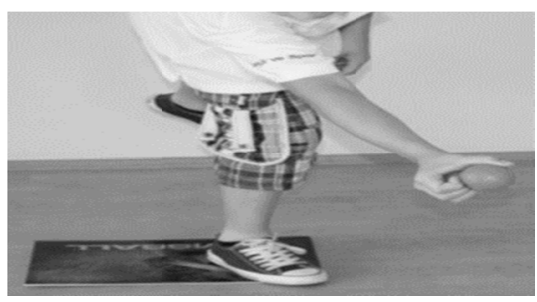

Tirnak: The arm is stretched and the ball is held by curling all the fingers except for the thumb and the ball is thrown forward by opening the fingers.

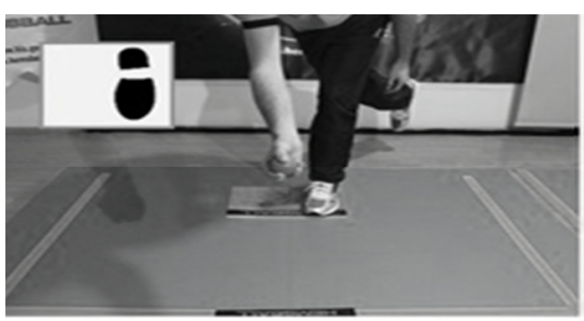

Teke: The ball is grasped by the first knuckles of the thumb, forefinger, and ring finger while it is placed on the curled middle finger. The ball is thrown by opening the fingers as the arm is moved forward.

Figure 2. Shooting Techniques

The hemsball training program applied to the experimental group is given below. 
Warm-up: 1. Throwing up and catching the ball held in the palm-up position of the hand by rolling it to the tip of the finger. 2. Throwing up the ball held in the palm-down position of the hand by stretching the wrist back from the fingertips and catching the ball with the same hand/another hand. 3. Throwing the ball held in the palm-up position of the dominant hand by circling the wrist from the inside out so that the ball goes out of the pinky finger. 4. Throwing up the ball after rotating it clockwise with three fingers and catching it in midair with the same hand/another hand. 5. Throwing the ball held on the back of the hand by stretching the wrist backward.

Hemsball Shooting Techniques: Applying the throwing techniques ( 8 throwing techniques) to the target board placed at a 3-meter distance to the wall. 2. Catching the ball returning from the wall by throwing the ball into the circle on the target board placed at a 3-meter distance to the wall. 3. Doing exercises in pairs with the shooting techniques on the game field.

Cooling-down: Stretching.

\subsection{Data Collection}

The fine motor proficiency and manual dexterity of hearing-impaired children were measured by The Bruininks Oseretsky Motor Proficiency Test (Bot-2), a widely used and reliable test (Bruininks and Bruininks, 2005). Fine motor proficiency and manual dexterity of hearing-impaired children were determined by the three sub-tests of Bot-2. Fine motor precision and fine motor integration, the two sub-tests of fine hand control, and manual dexterity, the sub-test of hand coordination, were used.

The three sub-tests of Bot-2, fine motor precision, fine motor integration, and manual dexterity, were performed twice; once before the 10-week program (pre-test), and the other at the end of 10 weeks (post-test). The three sub-tests of Bot-2, fine motor precision, fine motor integration, and manual dexterity were composed of a total of 20 items.

Fine motor precision sub-test was composed of 7 items (filling the circle like space- scribbling, filling the star-like space-scribbling, drawing lines to the target through the orbit-2 items, combining the dots, folding the paper, and cutting circles).

Fine motor integration sub-test was composed of 8 items (copying a circle, copying a square, copying the intersecting circles, drawing a trapezoid, drawing a triangle, drawing a rectangle, drawing a star, copying the intersecting pens).

The manual dexterity sub-test was composed of 5 items (making dots in the circles, transferring the stamps into the boxes, placing pawns in the holes of a punched box, classifying the cards, stringing the cube blocks).

All the children were given instructions on how to make measurements with Bot-2 and the whole experimental group was made to perform trial measurements before the main measurements to be able to ensure learning. The setting in which the measurements would be made was arranged in such a way that the setting was quiet and the children were not distracted. During the tests, children implemented the test guidelines in the best way and they were encouraged to be extremely careful.

\subsection{Data Analysis}

In the study, SPSS 18.0 for Windows Statistical Package Program was used to analyze the data obtained. Whether the data showed normal distribution was determined by Shapiro-Wilk and Kolmogorov-Smirnov tests. The comparisons between the groups (experimental-control) were performed by independent samples t-test and the comparisons between the measurements were performed by paired samples t-test. Besides, the interaction between groups and time was determined by repeated-measures two-way ANOVA. Also, in the study, power analysis (power analysis) was performed with $G^{*}$ Power 3.1.3 program for sample adequacy and it was calculated as $0.80(1-\beta)$ for 0.75 effect size.

\section{Results}

The results of the analysis regarding the effect of hemsball shooting techniques on fine motor proficiency and manual dexterity levels in hearing-impaired children were presented in Table 1. 
Table 1. Findings of the effect of hemsball shooting techniques on motor proficiency

\begin{tabular}{|c|c|c|c|c|c|}
\hline \multirow{2}{*}{ Tests } & \multirow{2}{*}{ Groups } & Pre-test & Post-test & \multirow{2}{*}{$\mathrm{p}$} & \multirow{2}{*}{ Change } \\
\hline & & $\overline{\mathrm{X}} \pm \mathrm{SD}$ & $\overline{\mathrm{X}} \pm \mathrm{SD}$ & & \\
\hline \multirow{3}{*}{ Fine motor precision } & Experimental & $27.76 \pm 6.66$ & $35.92 \pm 3.14$ & $<0.01$ & $\% 29.4$ \\
\hline & Control & $29.00 \pm 5.80$ & $28.38 \pm 6.34$ & $>0.05$ & - \\
\hline & $\mathrm{p}$ & $>0.05$ & $<0.01$ & & \\
\hline \multirow{3}{*}{ Fine motor integration } & Experimental & $28.00 \pm 6.29$ & $33.53 \pm 5.51$ & $<0.01$ & $\% 19.8$ \\
\hline & Control & $19.46 \pm 4.92$ & $18.84 \pm 4.21$ & $>0.05$ & - \\
\hline & $\mathrm{p}$ & $<0.01$ & $<0.01$ & & \\
\hline \multirow{3}{*}{ Manual dexterity } & Experimental & $25.61 \pm 4.95$ & $33.15 \pm 5.28$ & $<0.01$ & $\% 29.5$ \\
\hline & Control & $24.00 \pm 5.14$ & $24.23 \pm 5.13$ & $>0.05$ & - \\
\hline & $\mathrm{p}$ & $>0.05$ & $<0.01$ & & \\
\hline
\end{tabular}

According to the findings presented in Table 1, a significant difference was found between the experimental and control group, and between the pre-test and post-test mean scores $(\mathrm{p}<0.01)$. It was also found that the interaction between groups and time was not significant $(\mathrm{p}>0.05)$. When the arithmetic mean values were examined; it was determined that fine motor precision increased from $\bar{X}=27.76$ to $\bar{X}=35.92(29.4 \%$ of the increase $)$ in the experimental group; fine motor integration increased from $\bar{X}=28.00$ to $\bar{X}=33.53$ (19.8\% of the increase) and manual dexterity score increased from $\bar{X}=25.61$ to $\bar{X}=33.15$ ( $29.5 \%$ of the increase). On the other hand, the pre-test and post-test mean scores were found to be very close to each other in the control group (fine motor precision pre-test: $\bar{X}=29.00$ - post-test: $\bar{X}=28.38$; for fine motor integration pre-test: $\bar{X}=19.46$ - post-test: $\bar{X}=18.84$; manual dexterity pre-test: $\bar{X}=24.00$ - post-test: $\bar{X}=24.23$ ). These findings showed that hemsball shooting techniques had a significant effect on fine motor proficiency and manual dexterity levels.

The results regarding the comparison of the effect of hemsball shooting techniques on motor proficiency according to gender were presented in Table 2 .

Table 2. The comparison of the effect of hemsball shooting techniques on motor proficiency according to gender

\begin{tabular}{|c|c|c|c|c|c|c|c|}
\hline \multirow{3}{*}{ Tests } & & \multirow{2}{*}{\multicolumn{2}{|c|}{$\begin{array}{c}\text { Control Group } \\
\overline{\mathrm{X}} \pm \mathrm{SD}\end{array}$}} & \multirow{3}{*}{$\mathrm{p}$} & \multicolumn{2}{|c|}{ Experimental Group } & \multirow{3}{*}{$\mathrm{p}$} \\
\hline & & & & & & & \\
\hline & & Girl & Boy & & Girl & Boy & \\
\hline \multirow{3}{*}{$\begin{array}{l}\text { Fine motor } \\
\text { precision }\end{array}$} & Pre-test & $28.13 \pm 7.16$ & $30.40 \pm 2.70$ & & $28.00 \pm 9.93$ & $27.67 \pm 5.43$ & \\
\hline & Post-test & $27.38 \pm 8.00$ & $30.00 \pm 1.87$ & $>0.05$ & $35.50 \pm 3.42$ & $36.11 \pm 3.22$ & $>0.05$ \\
\hline & $\mathrm{p}$ & \multicolumn{2}{|c|}{$>0.05$} & \multicolumn{4}{|c|}{$<0.01$} \\
\hline \multirow{4}{*}{$\begin{array}{l}\text { Fine motor } \\
\text { integration }\end{array}$} & Pre-test & $19.88 \pm 5.33$ & $18.80 \pm 4.71$ & & $24.50 \pm 7.59$ & $29.56 \pm 5.39$ & \\
\hline & Post-test & $19.00 \pm 4.72$ & $18.60 \pm 3.78$ & $>0.05$ & $28.50 \pm 8.02$ & $35.78 \pm 1.79$ & $>0.05$ \\
\hline & $\mathrm{p}$ & \multicolumn{2}{|c|}{$>0.05$} & \multicolumn{4}{|c|}{$<0.01$} \\
\hline & Pre-test & $25.00 \pm 5.13$ & $22.40 \pm 5.32$ & & $28.25 \pm 1.71$ & $24.44 \pm 5.55$ & \\
\hline \multirow[t]{2}{*}{ Manual dexterity } & Post-test & $25.38 \pm 4.96$ & $22.40 \pm 5.41$ & $>0.05$ & $36.00 \pm 3.46$ & $31.89 \pm 5.62$ & $>0.05$ \\
\hline & $\mathrm{p}$ & \multicolumn{2}{|c|}{$>0.05$} & \multicolumn{4}{|c|}{$<0.01$} \\
\hline
\end{tabular}

According to the results of repeated measures two-way ANOVA, gender-time interactions were not found to be significant ( $p>0.05$ ). While no significant differences were observed according to gender and tests in the control group ( $>0.05$ ), the difference between fine motor precision, fine motor integration and manual dexterity mean scores was found to be significant in the experimental group both for girls and boys before and after the application (exercise) $(p<0.01)$. These findings indicated that the effect of hemsball shooting techniques on motor proficiency did not differ significantly according to gender and that the application performed had positive effects on both girls and boys.

\section{Discussion and Conclusion}

In this study, which was conducted to determine the effect of the exercises involving hemsball shooting techniques on fine motor proficiency and manual dexterity in hearing-impaired children between the age range of 7-11, the three sub-tests of Bot-2 (fine motor precision, fine motor integration, and manual dexterity) were used. With the belief that they would support the development of fine motor skills and manual dexterity, which are the requirements of these sub-tests, hemsball shooting techniques identified in this study were applied to 
hearing-impaired children. In the study, while the children in the experimental group (13 hearing impaired children) were subjected to a training program that involved hemsball shooting techniques for three days a week, one hour each day throughout 10 weeks, the children in the control group (13 hearing impaired children) solely continued their daily routine activities.

According to the results of the study, significant differences were found both between the experimental and control groups and between the pre-test and post-test mean scores. It was noted that while fine motor precision, fine motor integration, and manual dexterity mean scores of the experimental group increased, pre-test and post-test mean scores of the control group were quite close to each other.

It was determined that in hearing-impaired children, who exhibited delays in fine motor skills that affected both daily life and school activities, hemsball shooting techniques (alçacık, bilye, çatal, firıldak, firtına, tırnak, hortum and teke) required the synchronized use of wrist and fingers positively affected the development of fine motor precision, fine motor integration, and manual dexterity. In addition to this, it was revealed that the hemsball training program applied to the experimental group improved manual dexterity more when compared to fine motor precision and fine motor integration.

Grissmer, Grimm, Aiyer, Murrah, and Steele (2010), stated that fine motor skill was a strong predictor of school preparation, whereas Bala, Krneta, and Ratko (2010), emphasized that fine motor skill was sometimes involved in the pre-school assessment. The central vestibular pathway has a close structural and functional relationship with the auditory and sensory-motor systems. In other words, the vestibular system plays an important role in motor learning and development (Rashidi, Rasouli, Mohammadi, \& Heidari, 2017). There are plenty of studies that have reported that fine motor skill development is delayed in hearing-impaired children. In their study which compared the fine motor functions of hearing-impaired children aged between 7-13 and their normal-hearing friends, Rashidi et al. (2017) found that the total fine motor function scores of hearing-impaired children were significantly lower than normal hearing children. In another study on the children's (between the age range of 6-12) fine motor skill proficiencies, it was revealed that their manual dexterity sub-test scores in which there were the activities involving the manipulation of objects against time with an added component and there was a setting against time (such as putting on as many pegs as possible in 15 seconds) were lower than all the other sub-tests (Gaul \& Issartel, 2016). In the study conducted, while it was determined that manual dexterity sub-test scores were lower before the exercise, it was found out that there was a significant increase after the hemsball exercise program. Veiga, Santos, Silva and Pereira (2018) revealed as a result of their study investigating the motor proficiencies of children with and without hearing impairment that hearing-impaired children showed worse performance in manual dexterity, balance, and ball skills. Petrou et al. (2007) reported that the manual dexterity of hearing-impaired children was corrupted when compared to normal children.

Jernice and Nonis (2017) compared the gross and fine motor skills of female students with and without hearing impairments who were involved in the physical education classes in the integrated setting. They did not find any significant differences in gross and fine motor skills. However, they revealed that the hearing impaired group had significantly lower scores in kinesthetic integration compared to the hearing group. In their study, Gheysen et al. (2008) exhibited that the children between the age range of 4-12 with no hearing impairment were better in ball skills and dynamic and static balance skills as well as manual dexterity compared to hearing-impaired children. Furthermore, there are also studies supporting that hearing-impaired children have had a lower fine and gross motor skills than the children with no hearing impairment (Shaikh \& Sadhale, 2013; Gyton \& Hall, 2001). Horn, Pisoni, and Miyamoto (2006) revealed that hearing-impaired children who experienced their hearing impairment before their language acquisition and who had cochlear implant before they reached the age of 5 had gross motor skills close to their calendar age, whereas they found out that these children had delayed fine motor skills. In addition to this, they also noted that fine motor skills, contrary to gross motor skills, tended to exhibit more delays in the first degree deaf children as they grow up.

In another study, researchers reported that children with language problems experienced difficulties regarding manual dexterity (bimanual coordination and eye-hand coordination) (Estil, Whiting, Sigmundsson \& Ingvaldsen, 2003). This situation is in parallel with the present study. With hemsball shooting techniques performed with a 45-55 $\mathrm{mm}$ rubber hemsball ball which has special reliefs on the surface for easy grip, hemsball is considered as an alternative sport for hearing impaired children experiencing delays in manual dexterity. The shooting techniques like bilye, çatal, firıldak, hortum, tırnak and teke together with alçacık and firtına shooting techniques in which the wrist joint is active, are deemed important for the development of manual dexterity.

According to the results of the study, significant differences were found both between the experimental and control groups and between the pre-test and post-test mean scores. As a result of this research, it was determined 
that hemsball shooting techniques had a positive effect on the fine motor proficiency level of hearing-impaired children which involved fine motor precision, fine motor integration, and manual dexterity. In his study on hemsball game skills, Işık (2016) found that hemsball had a positive effect on the development of bilateral and upper extremity coordination in children with mental disabilities.

In this study, it was determined that the effect of hemsball shooting techniques on motor proficiency did not show a significant difference according to gender, and more explicitly, the application made created a positive effect in both girls and boys. Together with the fact that studies are supporting the results of the present study (Pitchford, Papini, Outhwaite, \& Gulliford, 2016; S. Mortazavi, Z. Mortazavi, \& Mirbagheri, 2016), there are also studies reporting exactly the opposite (McPhillips \& Jordan-Black, 2007; Morley, Till, Ogilvie, \& Turner, 2015). In their study, Pitchford et al. (2016) emphasized that there was no significant interaction between genders and that fine motor skills developed similarly both in boys and in girls. Mortazavi et al. (2016) reported the comparative results of their research on hearing-impaired students between the age range of 7-11 and expressed that gender did not play an effective role in the acquired good skill scores. On the other hand, McPhillips et al. (2007) revealed that girls were superior to boys in dexterity-related tasks, and Morley et al. (2015) noted that the girls between the age range of 4-7 performed better than the boys in all the tasks regarding motor skills. Physical activity programs designed or structured to be able to meet the specific needs of hearing-impaired children can contribute to the development of motor skills, especially in this group.

The fact that there is low or no auditory input negatively affects the cognitive, affective, social, academic, and motor development stages of hearing-impaired children. Even though many activities are carried out to minimize this negativity, fulfilling applications that might be more beneficial and/or more effective in a very short time can be put forward as a result of scientific studies. It has been revealed in this study that the shooting techniques of hemsball, which is a new sports branch, have created a positive effect on fine motor proficiency and manual dexterity level in hearing-impaired children. Hemsball is an alternative sports branch in which hearing-impaired children who are restricted in many areas can easily set up and play without the requirement for more space. On the other hand, the studies to be conducted on the sample groups with different kinds of disabilities and different age groups regarding hemsball exercises may contribute to the literature as well as forming a source of data for the relevant people and institutions. Furthermore, this study demonstrates the importance of developing hearing impaired children's motor skill performances that can positively contribute to their fine motor skills.

\section{Acknowledgments}

The study was approved by the clinical research ethics committee decision at Afyon Kocatepe University Faculty of Medicine (No: 35095782). Moreover, this study was supported by the Scientific Research Projects Commission of Afyon Kocatepe University (Project No: 17.KARIYER.96)

\section{References}

Bala, G., Krneta, Ž., \& Katić, R. (2010). Effects of kindergarten period on school readiness and motor abilities. Collegium antropologicum, 34(1), 61-67.

Bruininks, R. H., \& Bruininks, B. D. (2005). Bruininks-Oseretsky Test of Motor Proficiency (2nd ed.). Minneapolis, MN: NCS Pearson. https://doi.org/10.1037/t14991-000

Case-Smith, J., \& O’Brien, J. C. (2013). Occupational therapy for children-E-Book. Elsevier Health Sciences.

Estil, L. B., Whiting, H. T. A., Sigmundsson, H., \& Ingvaldsen, R. P. (2003). Why might language and motor impairments occur together?. Infant and Child Development: An International Journal of Research and Practice, 12(3), 253-265. https://doi.org/10.1002/icd.289

Fisher, A., Reilly, J. J., Kelly, L. A., Montgomery, C., Williamson, A., Paton, J. Y., \& Stan G. (2005). Fundamental movement skills and habitual physical activity in young children. Medicine and Science in Sports and Exercise, 37(4), 684-688. https://doi.org/10.1249/01.mss.0000159138.48107.7d

Gallahue, D., \& Ozmun, J. (1995). Fundamental Movement Abilities. In S. Spoolman (Ed.), Understanding Motor Development: Infant, Children Adolescents, Adults (3rd ed., pp. 223-404). Wisconsin-Iowa: Brown \& Benchmark.

Gaul, D., \& Issartel, J. (2016). Fine motor skill proficiency in typically developing children: On or off the maturation track?. Human movement science, 46, 78-85. https://doi.org/10.1016/j.humov.2015.12.011

Gheysen F., Loots G., \& Waelvelde H. V. (2008), Motor development of deaf children with and without cochlear implants. Journal of Deaf Studies and Deaf Education, 13(2), 215-224. https://doi.org/10.1093/deafed/enm053 
Gönülateş, S. (2017). Her Yaş için Spor Hemsball [Sport Hemsball For All Ages]. Akademisyen Kitabevi.

Grissmer, D., Grimm, K. J., Aiyer, S. M., Murrah, W. M., \& Steele, J. S. (2010). Fine motor skills and early comprehension of the world: Two new school readiness indicators. Developmental Psychology, 46(5), 1008-1017. https://doi.org/10.1037/a0020104

Gyton, A. C., \& Hall, J. E. (2001). Textbook of medical physiology. Function of cerebral cortex in hearing (10th ed.). Noida. Harcourt, Asia PTE Limited.

Häger-Ross, C., \& Rösblad, B. (2002). Norms for grip strength in children aged 4-16 years. Acta Paediatrica, 91(6), 617-625. https://doi.org/10.1111/j.1651-2227.2002.tb03290.x

Hemsball (2011). The history of hemsball, rules and explanations got from. Retrieved from http://www.hemsball.com/2-hemsball.html

Horn, D. L., Pisoni, D. B., \& Miyamoto, R. T. (2006). Divergence of fine and gross motor skills in prelingually deaf children: Implications for cochlear implantation. The Laryngoscope, 116, 1500-1506. https://doi.org/10.1097/01.mlg.0000230404.84242.4c

Horvat, M. A. (1990). Student Workbook and Practicum Guide to Accompany Physical Education and Sports for Exceptional Students. WC Brown Publishers.

Houwen, S., Visscher, C., Lemmink, K. A., \& Hartman, E. (2009). Motor skill performance of children and adolescents with visual impairments: A review. Exceptional Children, 75(4), 464-492. https://doi.org/10.1177/001440290907500405

Işı, M. (2016). The effects of the game hemsball on the motor skills proficiency results of mentally disabled children. Gazı University Institute of Health Sciences, Ankara.

Ișik, M., \& Zorba E. (2018). The effects of hemsball on the motor proficiency of students with intellectual disabilities. https://doi.org/10.1080/20473869.2018.1488534

Jernice, T. S., \& Nonis, K. (2017). The Motor Skills of Adolescents with Hearing Impairment in a Regular Physical Education Environment. International Journal of Special Education, 32(3), 596-607.

Krombholz, H. (2006). Physical performance in relation to age, sex, birth order, social class, and sports activities of preschool children. Perceptual and Motor Skills, 102, 477-484. https://doi.org/10.2466/pms.102.2.477-484

McPhillips, M., \& Jordan-Black, J. A. (2007). The effect of social disadvantage on motor development in young children: a comparative study. Journal of Child Psychology and Psychiatry, 48(12), 1214-1222. https://doi.org/10.1111/j.1469-7610.2007.01814.x

Melo, R. D. S., Lemos, A., Macky, C. F. D. S. T., Raposo, M. C. F., \& Ferraz, K. M. (2015). Postural control assessment in students with normal hearing and sensorineural hearing loss. Brazilian Journal of otorhinolaryngology, 81(4), 431-438. https://doi.org/10.1016/j.bjorl.2014.08.014

Moreira, R. S., Magalhães, L. C., \& Alves, C. R. (2014). Effect of preterm birth on motor development, behavior, and school performance of school-age children: A systematic review. Jornal de pediatria, 90(2), 119-134. https://doi.org/10.1016/j.jped.2013.05.010

Morley, D., Till, K., Ogilvie, P., \& Turner, G. (2015). Influences of gender and socioeconomic status on the motor proficiency of children in the UK. Human movement science, 44, 150-156. https://doi.org/10.1016/j.humov.2015.08.022

Mortazavi, S. S., Mortazavi, Z., \& Mirbagheri, S. S. (2016). Evaluation of the relationship between fine motor skills and demographic indices in students with hearing impairment. Physical Treatments-Specific Physical Therapy Journal, 6(2), 93-102. https://doi.org/10.18869/nrip.ptj.6.2.93

Payne, V. G., \& Isaacs, L. D. (2008). Human motor development: A life span approach (8th ed.). McGraw-Hill Companies, Inc.

Petrou, S., McCann, D., Law, C. M., Watkin, P. M., Worsfold, S., \& Kennedy, C. R. (2007). Health status and health-related quality of life preference-based outcomes of children who are aged 7 to 9 years and have bilateral permanent childhood hearing impairment. Pediatrics, 120(5), 1044-1052. https://doi.org/10.1542/peds.2007-0159

Pitchford, N. J., Papini, C., Outhwaite, L. A., \& Gulliford, A. (2016). Fine motor skills predict maths ability better than they predict reading ability in the early primary school years. Frontiers in psychology, 7, 783. 
https://doi.org/10.3389/fpsyg.2016.00783

Rajendran, V., \& Roy, F. G. (2011). An overview of motor skill performance and balance in hearing impaired children. Italian journal of pediatrics, 37(1), 1-5. https://doi.org/10.1186/1824-7288-37-33

Rapin, I. (1974). Hypoactive labyrinths and motor development. Clinical Pediatrics, 13(11), 922-937. https://doi.org/10.1177/000992287401301103

Rashidi, Z., Rasouli, F., Mohammadi, H., \& Heidari, A.(2017). Comparison of fine motor function between children with profound hearing loss and those with normal hearing. Journal of North Khorasan University of Medical Sciences, 8(3), 417-425. https://doi.org/10.18869/acadpub.jnkums.8.3.417

Rine, R. M., Cornwall, G., Gan, K., LoCascio, C., O'Hare, T., Robinson, E., \& Rice, M. (2000). Evidence of progressive delay of motor development in children with sensorineural hearing loss and concurrent vestibular dysfunction. Perceptual and motor skills, 90(3_suppl), 1101-1112. https://doi.org/10.2466/pms.2000.90.3c.1101

Sever, O., Gonulates, S., Bayraktar, A., Erdal, A. Z., Gerek, Z., \& Ipekoglu, G. (2016). The effect of 8-week hemsball training on balance, reactive agility and lower extremity strength. Türk Spor ve Egzersiz Dergisi, 18(3), 78-83.

Shaikh, A. A., \& Sadhale, A. (2013). Motor proficiency in hearing impaired and healthy children: A comparison. International Journal of Current Research and Review, 5(11), 57-63.

Smith, Y. A., Hong, E., \& Presson, C. (2000). Normative and validation studies of the Nine-hole Peg Test with children. Perceptual and motor skills, 90(3), 823-843. https://doi.org/10.2466/pms.2000.90.3.823

Suarez, H., Angeli, S., Suarez, A., Rosales, B., Carrera, X., \& Alonso, R. (2007). Balance sensory organization in children with profound hearing loss and cochlear implants. International journal of pediatric otorhinolaryngology, 71(4), 629-637. https://doi.org/10.1016/j.ijporl.2006.12.014

Todorova, R., Dimkova, R., Valova, T., \& Marcheva, P. (2014). Hemsball Game and its İnfluence On Handicapped Children's Psychopsysical Condition and the Familys Opinion. International Journal of Science Culture and Sport, 2(5), 665-693. https://doi.org/10.14486/IJSCS138

Tuğlu, B. (2016). The development process of hemsball according to the views of hemsball coaches. International Journal of Educational Research Review, 1(2), 34-41. https://doi.org/10.24331/ijere.309965

Veiga, G., Santos, M., Silva, B. S., \& Pereira, C. (2018). Motor competence in preschoolers with and without hearing loss. Proceedings of the 4th IPLeiria's International Health Congress BMC Health Services Research, 18(Suppl 2), 684. https://doi.org/10.1186/s12913-018-3444-8

Wiegersma, P. H., \& Velde. V. A. (1983). Motor Development of Deaf Children. Journal of Experimental Child Psychology, 24(1), 103-111. https://doi.org/10.1111/j.1469-7610.1983.tb00107.x

Winnick, J. P. (2005). Adapted Physical Education and Sports (4th ed.). Human Kinetics.

Wrotniak, B. H., Epstein, L. H., Dorn, J. M., Jones, K. E., \& Kondilis, V. A. (2006). The relationship between motor proficiency and physical activity in children. Pediatrics, 118(6), e1758-e1765. https://doi.org/10.1542/peds.2006-0742

Yaman, N. G. U., \& Erturan, N. (1999). 6-10 yaş arası çok ileri derecede işitme engelli çocukların algı, bellek ve küçük kas motor gelişimlerinin incelenmesi. M.Ü. Atatürk Eğitim Fakültesi Eğitim Bilimleri Dergisi, 11, 379-404.

\section{Copyrights}

Copyright for this article is retained by the author(s), with first publication rights granted to the journal.

This is an open-access article distributed under the terms and conditions of the Creative Commons Attribution license (http://creativecommons.org/licenses/by/4.0/). 